\title{
Clareamento pela técnica de Power Bleaching em elemento estético desvitalizado -
}

\section{Relato de Caso Clínico}

\author{
Whitening using the Power Bleaching technique in a devitalized aesthetic element - Clinical Case
} Report

Blanqueamiento con la técnica Power Bleaching en un elemento estético desvitalizado - Reporte de caso clínico

\author{
Adriane Nascimento Alfaia \\ ORCID: https://orcid.org/0000-0003-2317-3935 \\ Centro Universitário Fametro, Brasil \\ E-mail: dricaaalfaia@gmail.com \\ Camila Quézia Nascimento Freitas \\ ORCID: https://orcid.org/0000-0002-6309-4054 \\ Centro Universitário Fametro, Brasil \\ E-mail: camilaquezianascimntofreitas@gmail.com \\ Gezaias Reis Lopes \\ ORCID: https://orcid.org/0000-0001-7060-6241 \\ Centro Universitário Fametro, Brasil \\ E-mail: reisgezaias@gmail.com \\ Luciana Onety Ramalho \\ ORCID: https://orcid.org/0000-0003-4100-860X \\ Universidade Federal do Amazonas, Brasil \\ E-mail: luciana_onety@hotmail.com \\ Juliana Lopes de Sá \\ ORCID: https://orcid.org/0000-0002-1927-2191 \\ Universidade Federal do Amazonas, Brasil \\ E-mail: julianalopesdesa@hotmail.com
}

\begin{abstract}
Resumo
Objetivo: O presente estudo relata um caso clínico de clareamento pela técnica de power bleaching em elemento estético desvitalizado Metodologia: Trata-se de um relato de caso clínico de cunho analítico descritivo (Pereira et al., 2018). Relato de Caso: Paciente T.P.F, gênero feminino, 41 anos, compareceu a Clínica de Odontologia do Centro Universitário Fametro, com queixa principal "baixa autoestima por apresentar um dente mais amarelado que os outros devido tratamento de canal realizado por volta de oito anos". Na anamnese, a paciente relatou gozar de boa saúde, não possui doenças sistêmicas, hábito para funcionais, alergias e sensibilidades a medicamentos e alimentos. Conclusão: Conclui-se que o clareamento pela técnica imediata conhecida como power bleaching, tornou o procedimento seguro e com um resultado satisfatório, melhorando a estética do sorriso e elevando a autoestima da paciente.
\end{abstract}

Palavras-chave: Clareamento; Dente; Clareadores; Dente não vital.

\begin{abstract}
Objective: The present study is related to a clinical case of whitening using the energy whitening technique in a devitalized aesthetic element Methodology: This is a clinical case report of descriptive analytical nature (Pereira et al., 2018). Case Report: Patient T.P.F, female, 41 years old, attended the Dentistry Clinic of Centro Universitário Fametro, with the main complaint "low self-esteem for having a tooth that is yellower than the others due to root canal treatment performed at around eight years of age". In the anamnesis, the patient reported enjoying good health, no systemic diseases, no parafunctional habits, allergies and sensitivities to medications and foods. Conclusion: It is concluded that whitening by the immediate technique known as energy whitening, made the procedure safe and with a satisfactory result, improving the aesthetics of the smile and raising the patient's self-esteem.
\end{abstract}

Keywords: Whitening; Tooth; Whiteners; Non-vital tooth.

\section{Resumen}

Objetivo: El presente estudio se relaciona con un caso clínico de blanqueamiento mediante la técnica de blanqueamiento energético en un elemento estético desvitalizado Metodología: Se trata de un caso clínico de naturaleza analítica descriptiva (Pereira et al., 2018). Caso clínico: Paciente TPF, mujer de 41 años, acudió a la Clínica de Odontología del Centro Universitário Fametro, con la principal queja "baja autoestima por tener un diente 
más amarillento que los demás debido a un tratamiento de conducto realizado alrededor de los ocho años de edad". En la anamnesis, el paciente refirió gozar de buena salud, sin enfermedades sistémicas, sin hábitos parafuncionales, alergias y sensibilidades a medicamentos y alimentos. Conclusión: Se concluye que el blanqueamiento mediante la técnica inmediata conocida como blanqueamiento energético, hizo que el procedimiento fuera seguro y con un resultado satisfactorio, mejorando la estética de la sonrisa y elevando la autoestima del paciente.

Palabras clave: Blanqueamiento; Dental; Blanqueadores; Diente no vital.

\section{Introdução}

Com a evolução da odontologia estética, o clareamento dental tem sido destaque na sociedade nos dias atuais, na qual a visão sobre o sorriso vai além da função mastigatória. Dentes brancos, contornados e bem alinhados, vem sendo requisitado em grande demanda, sendo esse um novo padrão na qual tem sofrido grande influência na autoestima e bem esta (Bispo, 2018).

O clareamento dental é uma alternativa conservadora que alcança resultados satisfatórios em relação à cor, porém, o paciente deve ser conscientizado de que não é garantido totalmente um resultado satisfatório. É um procedimento seguro quando avaliado clinicamente de forma correta, na qual é imprescindível avaliar a condição periodontal, higiene oral, tempo de tratamento endodôntico e protocolo científico escolhido sobre a técnica executada. Além de ser um procedimento minimamente invasivo, o custo é consideravelmente baixo comparado a outros procedimentos estéticos, tais como lentes de contato, laminados cerâmicos e coroas protéticas. (Canuto, Araújo, Gomes et al., 2020)

Antes da execução do procedimento, é necessária que seja feita a avaliação física para investigar a idade do(a) paciente, condições sistêmica, avaliação clínica e radiográfica, pois se apresentar fratura da coroa, cárie, restauração insatisfatória, contaminação do canal radicular, gengivite ou periodontite, é vedada a prática até que as alterações citadas sejam tratadas previamente. (Rocha, Cunha, Cordeiro et al., 2020)

As opções de clareamento são por meio interno e/ou externo. O procedimento interno visa restaurar a coloração dos dentes despolpados com alteração provenientes de fatores intrínsecos como traumatismo, uso de tetraciclina, resquícios de material obturador. O externo por fatores extrínsecos, como pigmentação advinda de alimentos ricos em corante, tártaro, nicotina, que são normalmente de fácil remoção. (Vieira, Pinto, Dias et al., 2021)

Há uma diversidade de técnicas que são utilizadas para o clareamento dental interno, e uma delas é "Power Bleaching" também conhecida como clareamento endógeno imediato, no qual o agente clareador é aplicado no espaço da câmara pulpar e na face vestibular simultaneamente. O agente clareador, nesse caso, é aplicado a cada sessão realizada em conjunto, até que se obtenha o resultado esperado. (Boaventura, Roberto, Lima et al., 2012)

Na técnica de clareamento endógeno os agentes mais utilizados são, o peróxido de hidrogênio, peróxido de carbamida e o perborato de sódio. O agente peróxido de hidrogênio possui um peso molecular baixo capaz de penetrar na estrutura dental, na qual ocorre um processo de oxidação, e assim o peróxido de hidrogênio é capaz de promover a quebra de ligações duplas de moléculas, reduzindo o escurecimento dental (Bispo, 2018).

Embora o clareamento interno seja considerado simples e seguro, são necessárias algumas precauções para um bom resultado, dentre as quais se destacam a utilização de barreira intracoronária cervical, cujo objetivo é evitar que agentes clareadores penetrem pelos túbulos dentinários, com finalidade de prevenir reabsorção radicular externa. (HenriquE, 2017)

Diante disso, o objetivo deste trabalho foi relatar um caso clínico de reabilitação estética do elemento 11 , com escurecimento por motivos endodônticos utilizando a técnica de power bleaching.

\section{Metodologia}

Partindo da permissão da paciente por meio do Termo de Consentimento Livre e Esclarecido (TCLE) em partilhar sua imagem para devido fim, o presente estudo trata de um relato de caso clínico de cunho analítico descritivo (Pereira et al., 
2018), realizado na clínica odontológica do CEUNI Fametro, na disciplina de estágio supervisionado em Clínica Integrada II, do curso de graduação do Centro Universitário Fametro.

\section{Resultados e Discussão}

Paciente T.P.F, gênero feminino, 41 anos, compareceu a Clínica de Odontologia do Centro Universitário Fametro, com queixa principal "baixa autoestima por apresentar um dente mais amarelado que os outros devido tratamento de canal realizado por volta de oito anos". $\mathrm{Na}$ anamnese, a paciente relatou gozar de boa saúde, não possui doenças sistêmicas, hábito para funcionais, alergias e sensibilidades a medicamentos e alimentos. Antes do exame clínico intraoral realizou-se profilaxia com pedra pomes misturada em pasta profilática (Figura 1-C), logo observou-se que o elemento 11 apresentava uma restauração palatina satisfatória, e com a cor mais amarelada comparada aos elementos adjacentes (Figura 1- A e B). Foi identificada a presença de mínimas retrações gengivais em todos os elementos de ambas as arcas. No exame radiográfico do elemento 11 foi avaliado o tratamento endodôntico satisfatório (Figura 1-D) em seguida foi realizado o registro de cor inicial dos elementos 11, 21, 22 e 23 (Figura 2). com a escala Vitapan ${ }^{\circledR}$ Classical (Figura 1).

Figura 1: A) Fotografia frontal com discrepância nítida de cor do elemento 1; B) Fotografia intra-bucal; C) Profilaxia com escova de Robson e pedra pomes misturada em pasta profilática; D) Registro radiográfico do elemento 11 satisfatório endodoticamente.

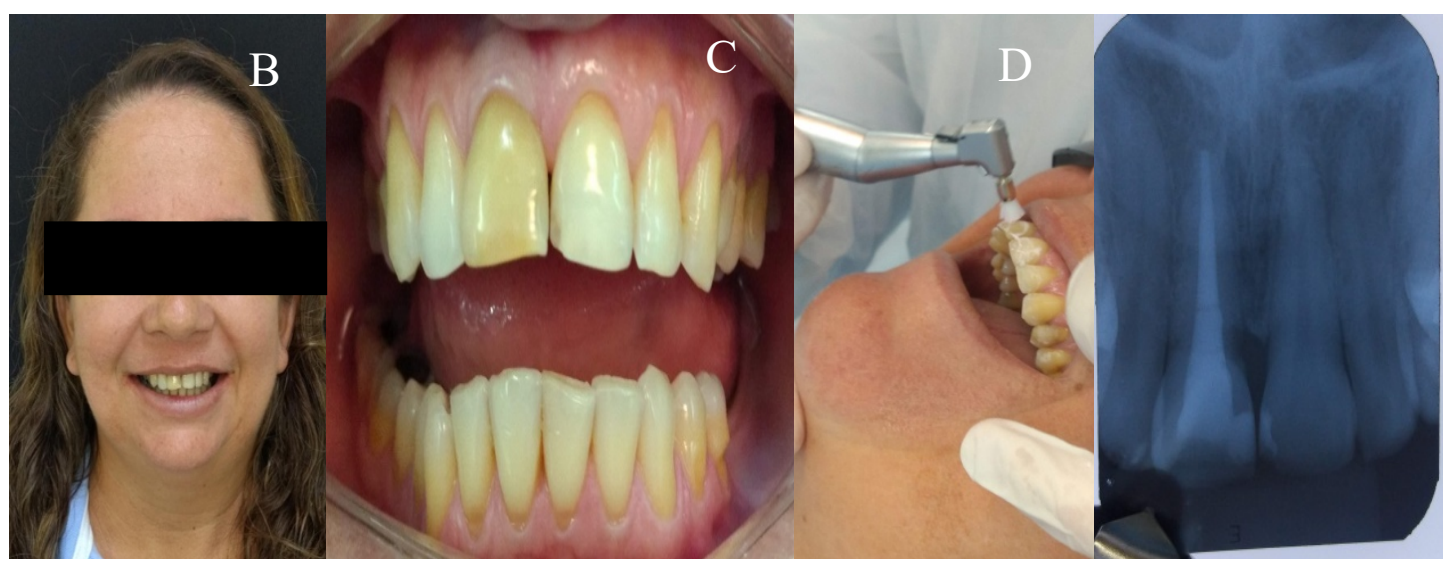

Fonte: Autores.

Figura 2: Registro de cor com Vitapan ${ }^{\circledR}$ Classical.

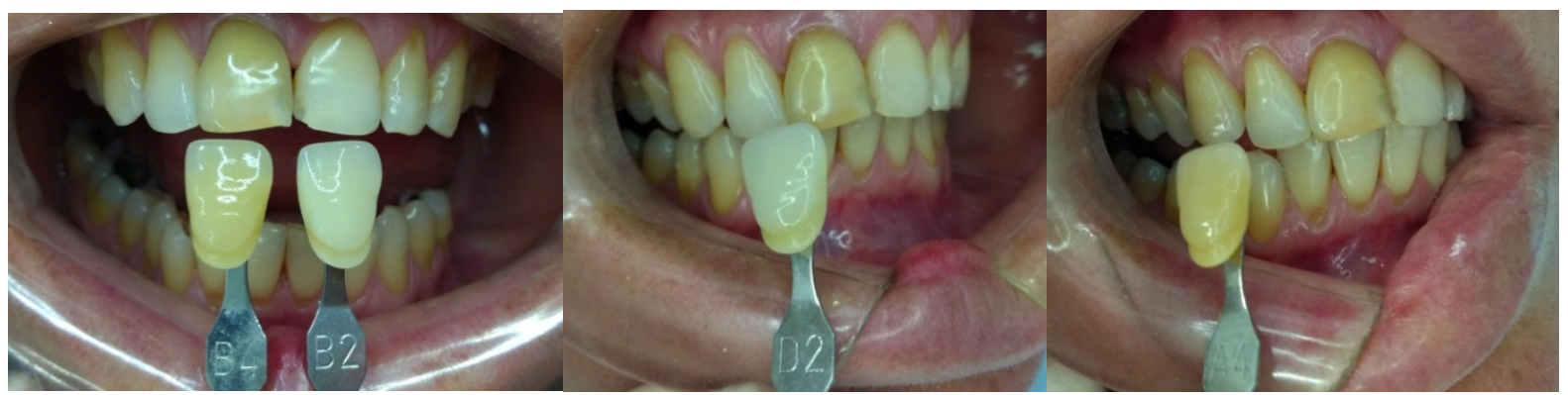

Fonte: Autores.

$\mathrm{Na}$ segunda consulta, após a profilaxia, foi feita a conferência da altura da coroa clínica com auxílio da sonda periodontal milimetrada Willians, a partir da borda incisal até a gengiva marginal, sendo a altura de $10 \mathrm{~mm}$ iniciou-se o acesso coronário através da face palatina no elemento $11 \mathrm{com}$ broca esférica diamantada 1013HL (Figura 8), forma de contorno 
preparada com broca diamantada 3118 (Figura 9). Adiante a remoção de 3mm do material obturador do terço cervical, com a broca gattes-glidden $\mathrm{n}^{\circ}$, seguido de lavagem com água destilada, secagem com papel absorvente estéril, toilet com bolinha de algodão estéril embebido em álcool $70 \%$ e volatização. Posteriormente foi realizada a confecção do tampão do terço cervical com a base maior voltada para a parede palatina, com ionômero de vidro fotopolimerizável ionoseal - voco, com propósito de proteger o tecido radicular do agente clareador e prevenir possíveis iatrogenias (Figura 3).

Figura 3: A) Mensuração com sonda milimetrada Willians, da altura da coroa clínica do elemento11; B) Mensuração na régua milimetrada de 10mm de altura da coroa clínica do elemento 11. C) Acesso coronário; D) Broca gates-glidden com stop travado em 13mm; E) Broca gates-glidden com stop travado em 13mm; F) Tampão cervical no elemento 11, com ionômero de vidro fotopolimerizável ionoseal - voco.
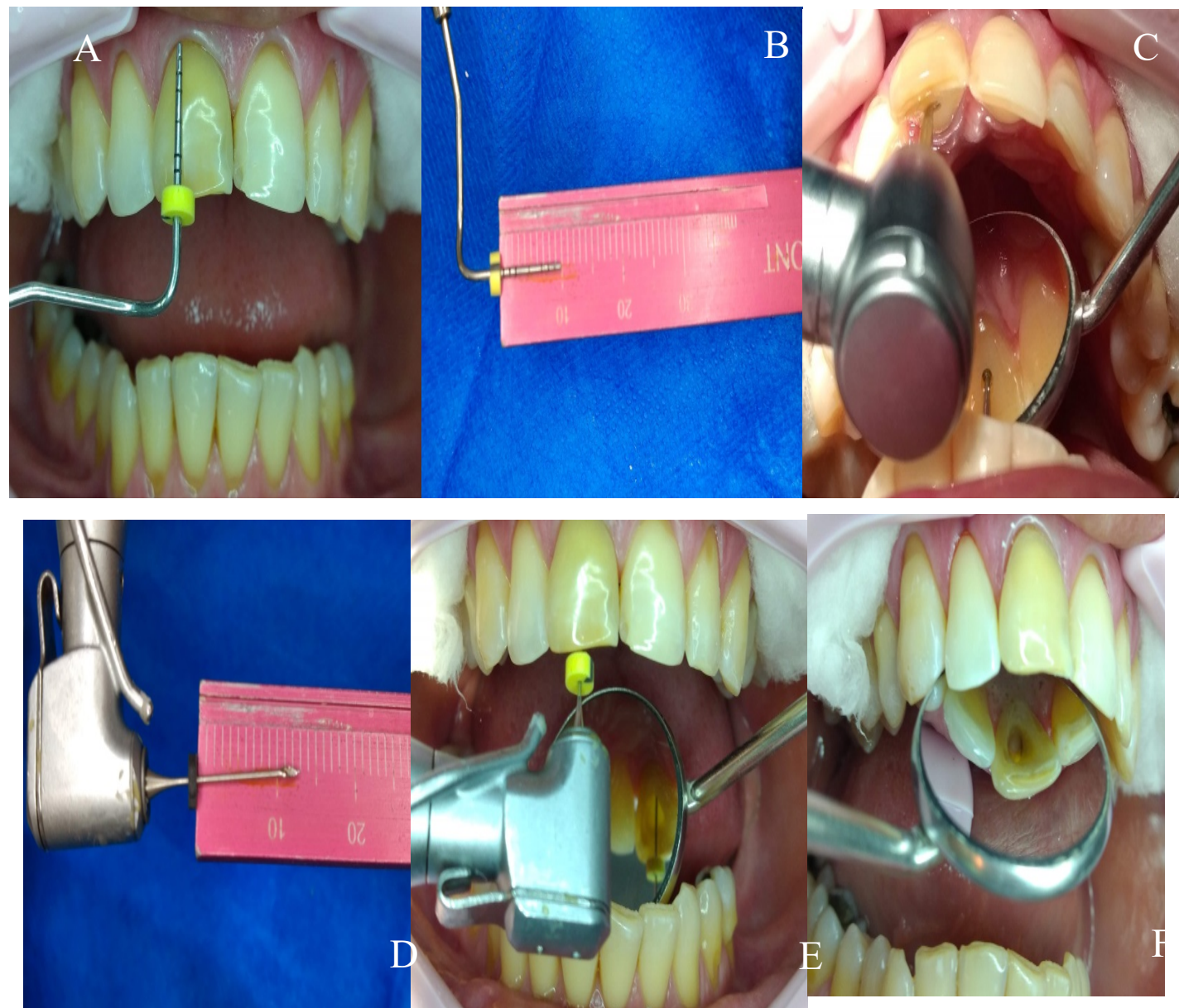

Fonte: Autores.

A seguir, foi instalado o afastador de lábio especialmente para clareamento, com dispositivo afastador de língua. Em seguida foi aplicada a barreira gengival - Potenza Blocco (PHS do Brasil), nas regiões cervicais recobrindo as recessões, gengiva marginal livre e papila, de dois em dois elementos e a face palatina somente do elemento 11, para evitar o contato do gel clareador com mucosa, sob riscos de injúrias. Realizou-se a acoplagem das seringas para a homogeneização do peróxido de hidrogênio a 38\% Potenza Bianco (PHS do Brasil) e o espessante. Na próxima etapa foi feita a aplicação do gel clareador na face vestibular dos dentes incisivos a segundo pré-molares superiores e inferiores pois a paciente havia solicitado o clareamento dos outros elementos, e inserido gel na área interna através da face palatina somente do elemento 11. Após aplicação em todos os dentes, o gel foi mantido durante 15 minutos, removido com auxílio de um sugador endodôntico de 
cânula fina e com gazes umedecidos em água destilada, para limpar resquícios. Logo se procedeu com mais duas reaplicações de 15 minutos cada uma. Ao longo do tempo ocorreu a movimentação do gel com micro aplicador descartável para eliminação de possíveis formações de bolhas (Figura 4).

Figura 4: A) homogeneização do peróxido de hidrogênio a 38\% e o espessante; B) Aplicação do gel clareador na face vestibular nos dentes incisivos a segundo pré-molares superiores e inferiores; C) Aplicação do gel clareador na área interna através da face palatina do elemento 11 .

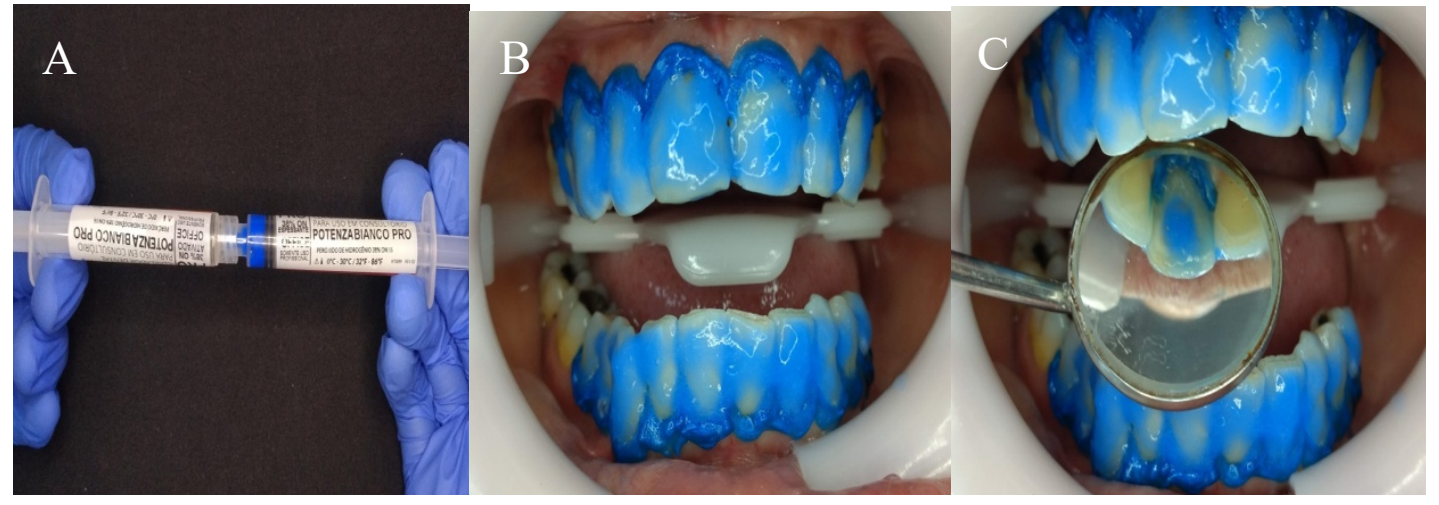

Fonte: Autores.

Após as três aplicações, sucedeu a remoção do gel com auxílio de um sugador. A barreira gengival foi removida com uma sonda periodontal milimetrada, seguido de lavagem com água abundante e secagem da cavidade com papel absorvente. Foi inserida uma bolinha de algodão para facilitar a abertura da câmara na próxima consulta sem perder a referência do tampão, e foi realizada uma restauração provisória com ionômero de vidro fotopolimerizável ionoseal - voco (Figura 5).

Figura 5: Restauração provisória

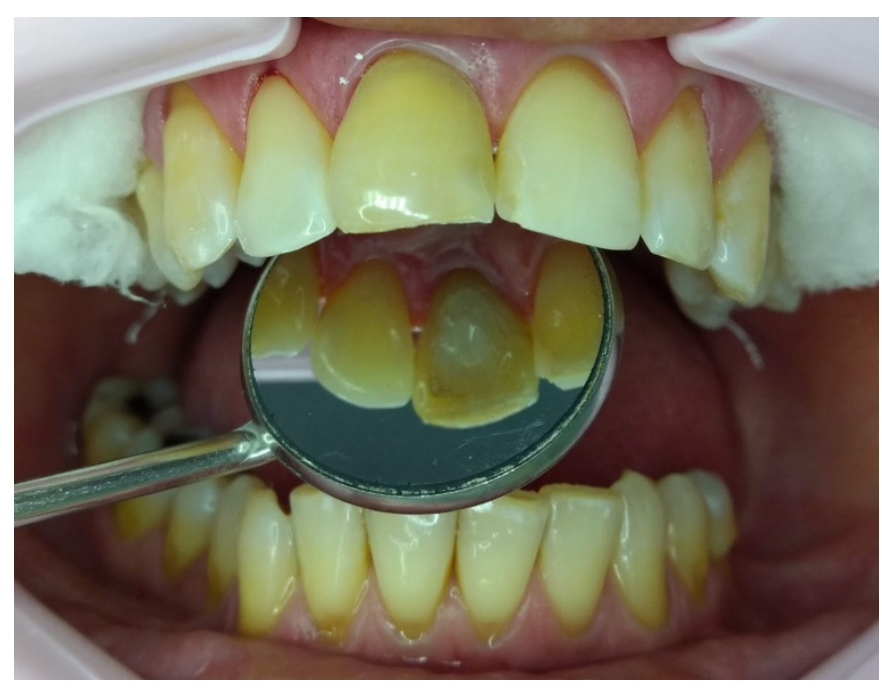

Fonte: Autores.

Na segunda sessão, novas fotografias foram registradas para a seleção de cor. Foi observado um resultado significante obtido na primeira sessão (Figura 6). O elemento 11 que possuía a cor inicial B4 se apresentou com a cor B3. 
Figura 6: A) Mensuração da cor com escala Vitapan ${ }^{\circledR}$ Classical após o resultado da primeira sessão de clareamento; B) Seleção de cor do resultado dos elementos 11 após a primeira sessão de clareamento.

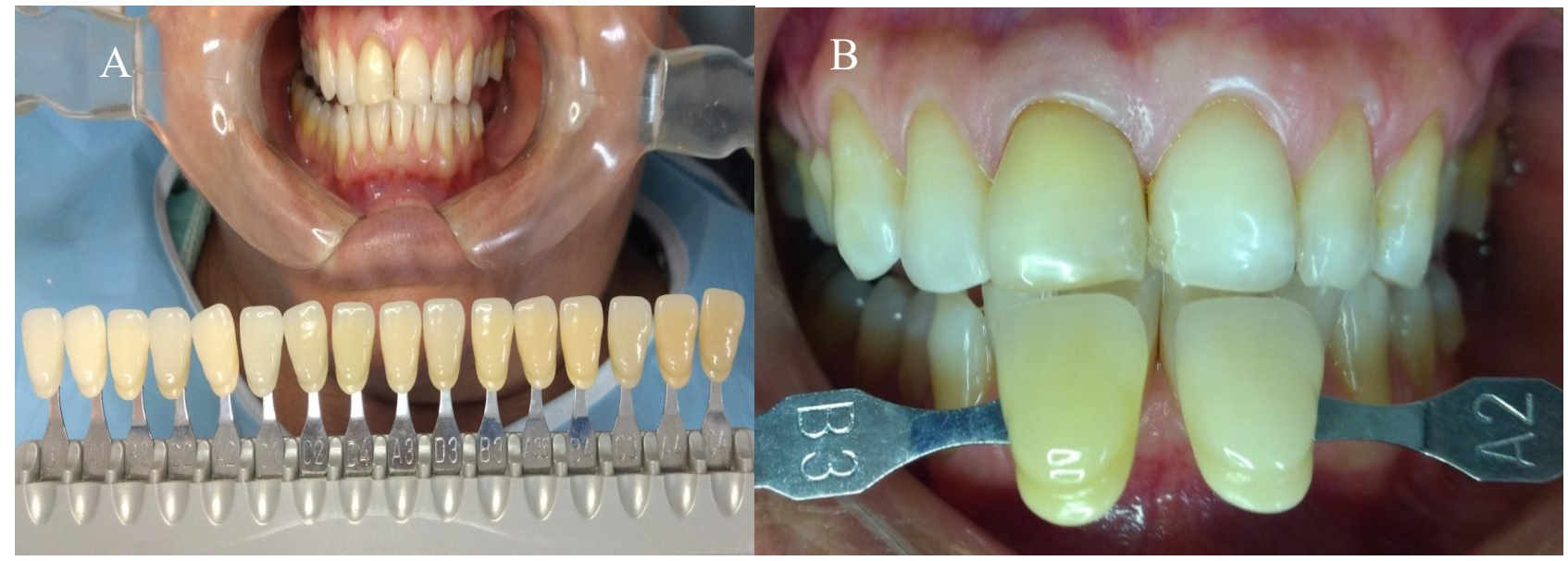

Fonte: Autores.

Procedeu-se com a remoção da restauração provisória do elemento 11, limpeza da câmara, isolamento com isotape dos elementos adjacentes e barreira gengival na face vestibular e palatina. Foram feitas novamente 3 aplicações de 15 minutos cada com peróxido de hidrogênio a $38 \%$ de forma externa e interna somente no elemento 11, apresentando o resultado imediato na mudança de cor anterior de B3 para B2 (Figura 7).

Figura 7: A) Aplicação interna de peróxido de hidrogênio a 38\%; B) Resultado imediato na mudança de cor do elemento 11 de B3 para B2.

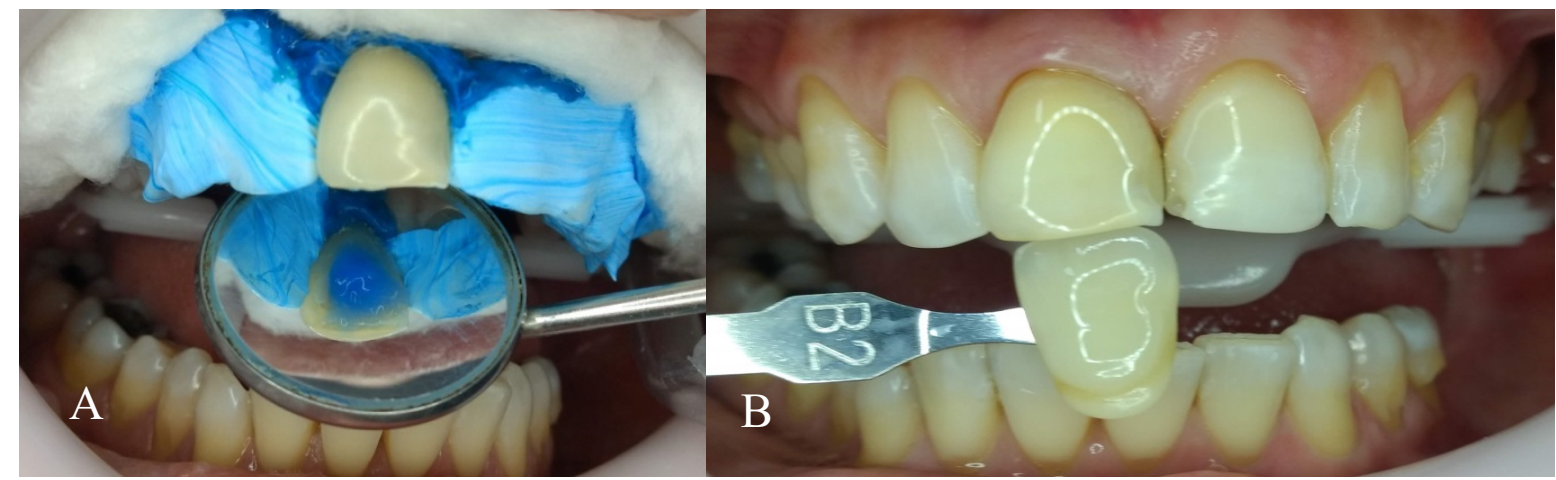

Fonte: Autores.

$\mathrm{Na}$ terceira consulta, o procedimento de clareamento imediato foi efetuado novamente no elemento 11 respeitando todo protocolo seguido anteriormente.

Após uma semana, a paciente retornou para o registro de cor final (figura 8), para a realização da restauração definitiva da face palatina do elemento 11 para a troca das restaurações mesiais do elemento 11 e 21 .

Após estes procedimentos o resultado obtido foi satisfatório, havendo a mudança de cor inicial B4 para A2 do elemento 11 tornando-o harmônico com os demais elementos (Figura 9). 
Figura 8: Registro de cor final.

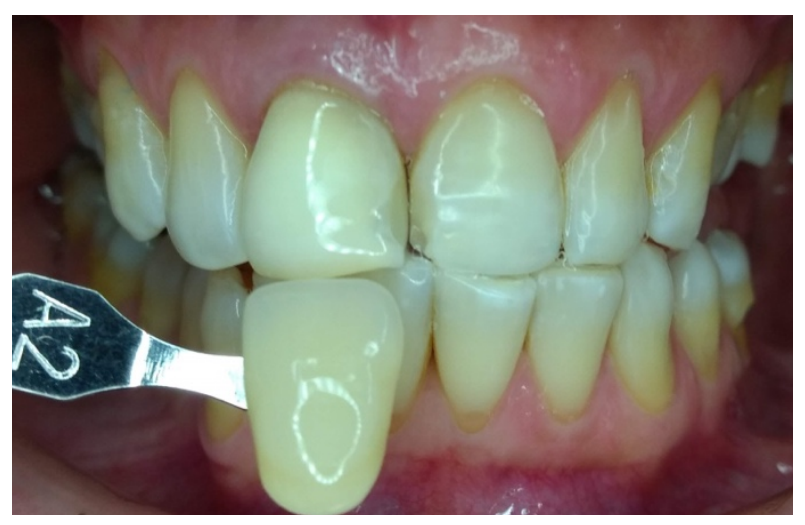

Fonte: Autores.

Figura 9: Registro de cor final.

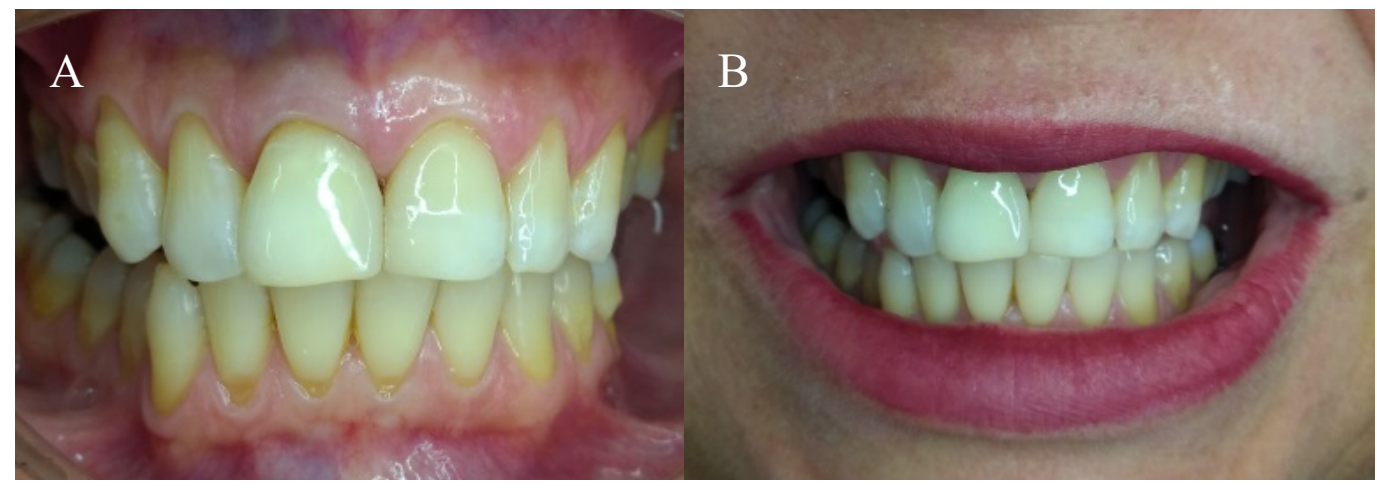

Fonte: Autores.

\section{Discussão}

O escurecimento dental é uma das queixas dos pacientes que realizaram tratamento endodôntico, comumente em dentes anteriores sendo considerados elementos estéticos por serem evidentes no sorriso. Uma das resoluções indicadas são os clareamentos endógenos, quando o paciente apresenta saúde bucal satisfatória após exame clínico detalhado (Canuto, Araújo \& Gomes, 2020; Fialho, Sousa \& Yamashita, 2021)

No caso presente a paciente possuía como queixa principal o escurecimento do elemento 11 ocorrido após alguns anos de tratamento endodôntico. Esta situação a levava a não sorrir e ter a autoestima baixa.

As alterações cromáticas intrínsecas são situadas por manchas locais decorrentes de traumatismo, hemorragia, medicamentos de uso intrapulpar, ineficácia do tratamento endodôntico, como a falha na limpeza da câmara pulpar deixando resquícios do material obturador, restos necróticos, provocando o escurecimento coronário (Bispo, 2018, Souza, Júnior \& Lopes, 2020, Fialho, Susa \& Yamashita, 2021).

É de grande importância ter o conhecimento dos fatores etiológicos provenientes da alteração de cor dental, para melhor diagnóstico e indicação de tratamento (Souza, Júnior \& Lopes, 2020).

No referido caso, a fim de se obter um correto diagnóstico do escurecimento, foi realizada uma radiografia e confirmada a presença de tratamento endodôntico no elemento 11, porém o mesmo estava satisfatório não necessitando a indicação de seu retratamento.

A técnica de clareamento endógeno é indicada para dentes escurecidos e com tratamento endodôntico e o seu objetivo é clarear o elemento a partir das estruturas internas para as externas. Para isso são recomendados alguns agentes clareadores de 
concentrações específicas e algumas técnicas. O peróxido de hidrogênio nas concentrações de 30 a $38 \%$ ou peróxido de carbamida $30 \%$ a $35 \%$, são os agentes indicados na técnica imediata também conhecida como "power bleaching", onde o gel clareador é aplicado na câmara pulpar e na face vestibular do elemento de forma simultânea, com 3 aplicações de 15minutos, totalizando o período de 45 minutos aproximadamente em uma sessão, caso seja preciso o processo é repetido em outras sessões (Souza, Júnior \& Lopes, 2020).

O perborato de sódio é um outro agente clareador empregue especificamente na técnica "walking bleaching", na qual consiste na mistura do perborato de sódio com água destilada. A mistura é aplicada dentro da câmara pulpar permanecendo em torno de 3 à 7 dias, protegida de um selamento cavitário, podendo o agente ser renovado de acordo com a necessidades do paciente. (Colón, Márquez, Cotto, et. al., 2021, Sobrinho, Rodrigues \& Esmeraldo, 2014).

Diante das diversas técnicas para clareamento de dentes desvitalizados, o caso relatado optou pela técnica de "power bleaching" utilizando como agente clareador o peróxido de hidrogênio a $38 \%$.

Um efeito adverso que pode ser causado pelo clareamento interno e que é considerado a maior preocupação é a reabsorção radicular. Esta reabsorção pode ocorrer devido ao agente clareador alcançar alguns tecidos periodontais provocando inflamações. (Júnior \& Lopes, 2020)

Para minimizar o risco de ocorrer a reabsorção externa e independente da técnica escolhida se faz necessária a confecção de um tampão cervical com o cimento de ionômero de vidro com o objetivo de reduzir os riscos da infiltração do gel para os tecidos periodontais. (Barbosa, Tavares, Batista, et al., 2020, Souza, Augusto, Aquino, et al., 2017).

Embora existam estudos que comprovem que o peróxido de hidrogênio em concentração elevada traga resultado imediato, em contrapartida, na sua maioria ocasionam possíveis reabsorções cervicais dependendo da concentração e tempo de contato do agente clareador como o de (Parreiras, Favoreto, Cruz, et al., 2020) há estudos como os de (Manna, Moreira, Medeiros, et al., 2021). que mostram como os efeitos colaterais resultantes do uso dos géis em alta concentração pode ser evitados. O tempo de contato do gel peróxido de hidrogênio comumente os de $\mathrm{pH}$ ácido, é recomendado em intervalos reduzidos, sendo o mais indicado 3 aplicações renovadas em 15 minutos em uma sessão. No citado artigo, verificou-se que as aplicações em tempo reduzido sugeridas, evitam a difusão intensa do agente nas estruturas internas, e a confecção do tampão cervical com CIV, restringe o efeito deletério, como a reabsorção cervical.

No caso relatado optou-se pelo uso do peróxido de hidrogênio a 38\%, através da técnica power bleaching e seguindo todos os cuidados sugeridos pelos autores (Manna, Moreira, Medeiros et al., 2021), com a confecção da barreira gengival e o tempo de aplicação do gel reduzido.

Os efeitos adversos ocasionados pelo clareamento, como por exemplo a reabsorção externa, podem ocorrer até sete anos após. (Milhomem pg 11). Para isso o paciente deverá ser observado logo após um mês desse tratamento e para consultas de rotina, sendo necessárias radiografias para análise do sucesso do tratamento.

No presente caso já houve a avaliação radiográfica após um mês do procedimento e não houve nenhuma alteração.

\section{Considerações Finais}

Conclui-se que o clareamento pela técnica imediata conhecida como power bleaching, realizada com o agente clareador peróxido de hidrogênio $38 \%$, seguindo os protocolos como a confecção do tampão cervical e tempo de ação do gel clareador, tornou o procedimento seguro e com um resultado satisfatório, melhorando a estética do sorriso e elevando a autoestima da paciente. 


\section{Referências}

Barbosa, T. B., Tavares, R. F., Batista, N. K., Lima, C. T., et. al. (2020). É necessário a restrição de corantes durante o clareamento? - Ciências Biológicas e de Saúde Unit, 6(1), 21-32.

Barbosa, D. C., De'stefani, T. P., Ceretta, B., et al. (2015). Estudo comparativo entre as técnicas de clareamento dental em consultório dental caseiro supervisionado em dentes vitais: uma revisão de literatura. Revista Odontol. Clín.-Cient. 27(3), 244-252.

Besegato, J. F., Matioli, I. A., Burey, A., et al. (2019). Associação de procedimentos para a resolução estética de dente com alteração de cor e tratado endodonticamente. Clinical and Laboratorial Reseach in Dentistry, Londrina.

Bispos L. B. (2018). Clareadores dentários contemporâneos: tópicos. Rev. Odontol. Univ. Cid. São. 30(2), $177-89$.

Boaventura, J. M. C, Roberto, A. R., Lima, J. P. M., et.al. (2012). Bleaching of pupless teeth: review of literature and comsiderations - Rev.Odontol.Univ., 114-122.

Canuto, L. C., Araújo, Y. B. M., Gomes, F. P., et al. (2020). Clareamento dental interno: relato de caso. Revista Eletrônica Acervo Saúde, Maceió, Sup.48, 1-8.

Cardoso, R. M., Cardoso, R. M., Júnior, P. C. M., et al. (2011). Clareamento interno: uma alternativa para discromia de dentes tratados endodonticamente. Revista Odontol. Clín.-Cient. (Online), Recife 10(2), 177-180.

Colón, V. E. V., Márquez, M. O. C., Cotto, R. A. C., \& Demarco, F. F. (2021). Dentist's preferences on vital and nonvital tooth bleaching: findings from a Guatemalan survey. Brazilian Journal of oral sciences, Guatemala,20.

Fialho, M. T., Sousa, P. H. D., \& Yamashita, R. K. (2021). Clareamento endógeno em dente desvitalizado: revisão de literatura - JNT - Facit Business and Technology Journal, 1, 326-334, Tocantins.

Henrique, D. B. B., et al. (2017). Os principais efeitos colaterais do clareamento dentário: como amenizá-los. Salusvita, $36(1), 141$ - 155.

Lucena M. T. L., Mantovani M., Fracalossi C., et. al. (2015). Clareamento interno em dentes desvitalizados com a técnica walking bleach - relato de caso. Revista Uningá Review, Maringá, 24(1), 33-39.

Manna, M. P. N. C., Moreira, R. H., Medeiros, Y. L., et al. (2021). Comparação sobre a eficácia e sensibilidade dos diferentes tipos de clareamento dental: uma revisão de literatura. 10(7), e12810716516.

Parreiras S. O., Favoreto M. W., Cruz G. P., et al. (2020). Concentração inicial e da câmara pulpar de peróxido de hidrogênio usando diferentes produtos de branqueamento, Braz Dent Sci, 23(2).

Rocha, M. S., Cunha, T. F. C., Cordeiro, N. A., et al. (2020). Reintervenção endodôntica e clareamento endógeno de dentes anteriores escurecidos: relato de caso. Revista Arch Health Invest, 9(2), 112-118.

Santos, M. R., Carvalho, F. B., Cangussu, M. C. T., \& Barros, L. R. (2020). Spectrophotometric analysis of the effectiveness of bleaching agents used for nonvital teeth bleaching. J Health Biol SCI. 8 (1): 1-6

Sobrinho, F. D. B. F., Rodrigues, R. A., \& Esmeraldo, F. U. P. (2014). Alternativas de Clareamento em Dentes Desvitalizados - Id on Line Revista de Psicologia, 8(23), 115- 125.

Souza, A. P, Júnior, O. C, Lopes, C. R. P., et al. (2020). Clareamento de dentes desvitalizados e escurecidos: uma revisão de literatura, JNT- Facit Business and Technology Journal 1,3-14, Tocantins.

Souza, C. R., Augusto, C. R., Aquino, E. P., et. al. (2017). Reabilitação estética de dente anterior escurecido: relato de caso - Arch Health Invest, 6(8), 377381 ,

Vieira, L. V., Pinto, T. A., Dias, C., et al. (2021). Internal whitening associated with external whitening of endodontically treated teeth - literature review. Brazilian jornal of Development, 7(4), 37052-37060. 